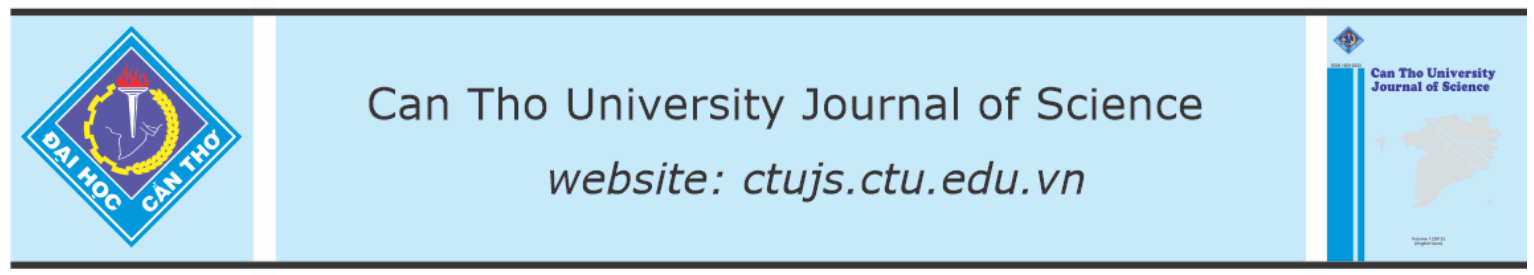

DOI: 10.22144/ctu.jen.2021.044

\title{
Estimating economic value of household municipal solid waste reduction program: A willingness-to-accept (WTA) approach
}

\author{
Huynh Thi Dan Xuan, Khong Tien Dung* and Huynh Viet Khai \\ College of Economics, Can Tho University, Viet Nam \\ *Correspondence: Khong Tien Dung (email: ktdung@ctu.edu.vn)
}

\section{Article info.}

Received 06 May 2021

Revised 18 Jun 2021

Accepted 02 Aug 2021

\section{Keywords}

Economic valuation, Mekong

Delta, solid waste

management, willing-to-

accept

\begin{abstract}
This study is aimed at estimating economic value of municipal solid waste (MSW) reduction program in the Mekong Delta by employing the willingness-to-accept (WTA) approach. This research will address two important issues in current growing literature about MSW management. First, this is the first research to evaluate economic value of the MSW reduction program in Mekong Delta. The second major contribution is the approach employed - supply curve through the WTA. This program requires community participation and provision incentives to them, therefore the requirement of public acceptance through WTA is estimated. Findings reveal that people are willing to accept an average of 30,000 $V N D / m o n t h$ for the MSW reduction program. Assume that household's MSW management fee subsidy policy is canceled, and the household is facing a full fee for the MSW collection (about 150,000 VND/month), they are willing to classify MSW at source to get a reduction of 30,000 VND or they are willing to accept a fee of 120,000 VND/month. In addition, it is interesting that more than 70 percent of people are willing to participate in this program. The determinants of WTA identified include the type of $M S W$ at the source, education level, type of urban areas. This research then proposes that MSW management implementation policy should be focused on motivating households and improving people's perception of MSW. In case of government budget deficit, community participation would be more appropriate to manage MSW.
\end{abstract}

\section{INTRODUCTION}

During the period 2009 to 2019, the Vietnamese urban population has increased $2.64 \%$ per year, this level is more than twice the average annual population growth rate of Vietnam and six times higher than the average population growth rate in rural areas (General Statistics Office of Viet Nam 2020). The increase in urban population is mainly due to the high migration flow from rural to urban areas. This is caused by the low and unstable income of people in rural areas, the effects of climate change (especially in the Mekong Delta [MD]), as well as rapid industrial development. The service sector of urban areas, especially in 6 major cities/provinces, has created an uneven distribution among regions (General Statistics Office of Viet Nam, 2020). Therefore, it results in pressure on all aspects of the urban area in particular and the environment in general. In addition, the rapid population growth has depleted natural resources such as water, energy, and raw materials to meet production and consumption demand. Accordingly, the amount of 
municipal solid waste (MSW) rapidly increases in urban areas, especially household solid waste. MSW in urban areas accounts for more than $50 \%$ of the total MSW volume of the country, increasing from 32,000 tons/day in 2014 to 35,624 tons/day in 2019 (Ministry of Natural Resources and Environment, 2015; 2019).

In Vietnam, the management of MSW still has many shortcomings including management qualifications, infrastructure capacity and financial capacity. Besides, the rate of MSW collection is not only high and classified at source, but also treatment technology is low. Therefore, MSW has created a lot of pressure on the environment and public health. Hence, the consolidation and completion of the MSW management system are very necessary. However, when this system runs better, the fee for MSW management service will be higher than the current one, which is inevitable. To determine this new fee, most studies estimated people's willingness to pay for improved MSW management services. For example, some (of them) include Alta and Deshaz (1996), Yusuf et al (2007), Chuen-Khee and Othman (2010), Niringiye and O Mortor (2010), Ojok et al. (2012) and Yuan and Yabe (2015) searched ways to improve solid waste management in Pakistan, Nigeria, Malaysia, Uganda and China, respectively.

With the growing literature on the MSW topic and resulting policy implication, several localities have implemented a program to classify MSW at the source. In addition, classifying waste at the source also contributes to creating raw materials for recycling activities, reducing the amount of MSW buried in landfills while the area sources for landfills are limited. The classification of MSW at source plays a decisive role and affects the entire solid waste management system. However, only some studies (Karousakis \& Birol, 2008; Victor et al., 2013; Laurent et al., 2013; Czajkowski et al., 2014) have examined the classification of MSW at source and there are still very few studies on the willingness to compensate for household MSW classification as it is inconvenient for households because it requires space, time and effort. The source generation requires community involvement or public acceptance measured by willingness to accept or the obligation to separate waste. As a result, it is necessary to identify the willingness to accept (WTA) that compensates for household MSW segregation at the source in MD. Based on research findings, WTA is measured to identify the optimum price of separated waste in order to improve program performance and also increase households' acceptance of this.

\section{LITERATURE REVIEW AND METHODOLOGY}

\subsection{General information of MSW classification program at the source in Vietnam and MD}

Decree 38 on waste and scrap management issued by the Prime Minister on 24 January 2015 stipulates that waste classification means separating the waste into categories or groups that are proceeded by different management. MSW is classified at source following management purposes and processed into the following groups: (i) biodegradable organic (leaves, vegetables, fruits, animals); (ii) reusable and recyclable (paper, plastic, metal, rubber, nylon, glass) and (iii) the other unclassified small items. The classification of MSW must be complied by households according to regulations, ensuring favorable requirements for collection, transportation, and treatment. MSW which is classified at source can also be according to the above groups or groups according to criteria suitable to specific natural, socio-economic conditions of each locality. For example, according to Can Tho City Department of Construction (2018), MSW is categorized into three groups namely (i) burnable group; (ii) non-burnable group, and (iii) the hazardous group to ensure the favorable requirements for the disposal of solid waste according to incineration methods. Meanwhile, Ben Tre province has also piloted source separation for the scrap, the organic part, and the rest (Ben Tre Provincial People's Committee, 2019).

The purpose of waste classification at source is to separate high recyclable waste at the household level, especially organic components with a high proportion of biodegradable $(60-80 \%)$ to create a "clean" organic source for high-quality composting. In addition, classifying waste at the source also contributes to creating raw materials for recycling activities, reducing the amount of MSW buried in landfills when the volume of MSW is increasing, while the area for landfill is limited. The classification of MSW at source plays a decisive role and affects the entire solid waste management system. So far, many localities across the country have also piloted programs to classify MSW at source such as Hanoi and Ho Chi Minh City (since 2007 and 1999), Bac Ninh (2014), Lao Cai (2016), Binh Duong (2017). In Can Tho city, this program has been implemented in 4 districts (Ninh Kieu, Binh Thuy, Cai Rang, and Thoi Lai) from 
September 2017. Several provincial reports have indicated that a part of people has understood and classified successfully. The current solid waste quality is eligible to be put into the treatment plants though there is still a small amount of incinerable in solid waste such as glass bottles, honeycomb charcoal, mini gas cylinders.

\subsection{Literature review on willingness to pay and willingness to accept}

Methods employed for non-market valuation include direct (or expression of preference) and indirect (or expression of preference) approaches (Pearce and Moran, 2013). The stochastic method is the most commonly used revealed preference method to estimate the monetary value of nonmarket goods through the use of hypothetical scenarios presented to respondents (Chien et al, 2005; Dupraz et al., 2003; Cooper et al., 2002; Cummings et al., 1995). Contingent valuation methodology (CVM) is often based on the use of maximum willingness to pay (WTP) to value the environmental quality improvement, property ownership, or non-market benefits (Mitchell and Carson, 2013; Kling et al., 2012; Wossink and Swinton, 2007; Hanley et al., 2003; Arrow et al., 1993). However, CVM can also be used to quantify the monetary value of minimum willingness to accept (WTA) to compensate individuals for environmental losses or to provide non-visual goods or benefits in situations where the definition of the good of interest is well defined (Small et al., 2017; Arrow et al., 1993; Del Saz-Salazar et al., 2009). Nevertheless, the CVM has been criticized for several perceived weaknesses that include, among others, the failure of respondents to incorporate their budgets in valuation decisions, embedding effect, and overestimation of values that might undermine the credibility of derived monetary estimates (Hausman, 2012, Diamond \& Hausman, 1994). Thus, various studies have called for the need to validate CVM by examining its consistency with economic theory (Haab \& McConnell, 2002, Carlsson \& Martinisson, 2001).
WTP is usually linked to a desirable change, and WTA compensation is associated with a negative change (Peterson, 2003). As Nguyen et al. (2021) suggested (Fig. 1) while using WTP, one needs to be explicit about what he or she is paying for, and one needs to be explicit about what she is being compensated for when using WTA. Every situation could result in mixed losses and gains, leading one to measure WTA for losers and WTP for gainers, using the WTP or WTA terminology. In Vietnam, when doing source-separation MSW at the household level, this activity is good $\left(\mathrm{U}^{0}<\mathrm{U}^{1}\right)$, then the compensating welfare measure is WTA. In this case, households' participation in MSW management in the form of waste separation and recycling, or should be addressed toward the "waste as income generator' at the household level (Singhirunnusorn et al., 2012). However, this program will only be successful if the residents support this or are willing to accept this program. In other words, community acceptance can be reflected by the WTA. In fact, based on the literature review, considered the at-source separation program is offered by government. Therefore, state reference of households was based on the reduction of a loss as households accept loss through WTA. It is the fact that they have to sacrifice time and other opportunities to classify waste. On the other hand, when considering this as a gain or as an environmental gain, then WTP is the right measure. Future studies should also be looking at this aspect in order to point this out to validate each other and also fulfill policy implications from these results. In this case, people's willingness to accept economic sacrifices to separate waste in terms of timeconsuming and other income opportunities instead of separating waste. There are community initiatives conducting waste separation, however, in the case of Vietnam, income is their incentive instead of environmental pollution reduction, public participation in separation activities is very low (Can Tho City Department of Construction, 2018). Therefore, in order to measure any effect of government programs, public acceptance in environments through at-source waste separation via WTA is necessary. 


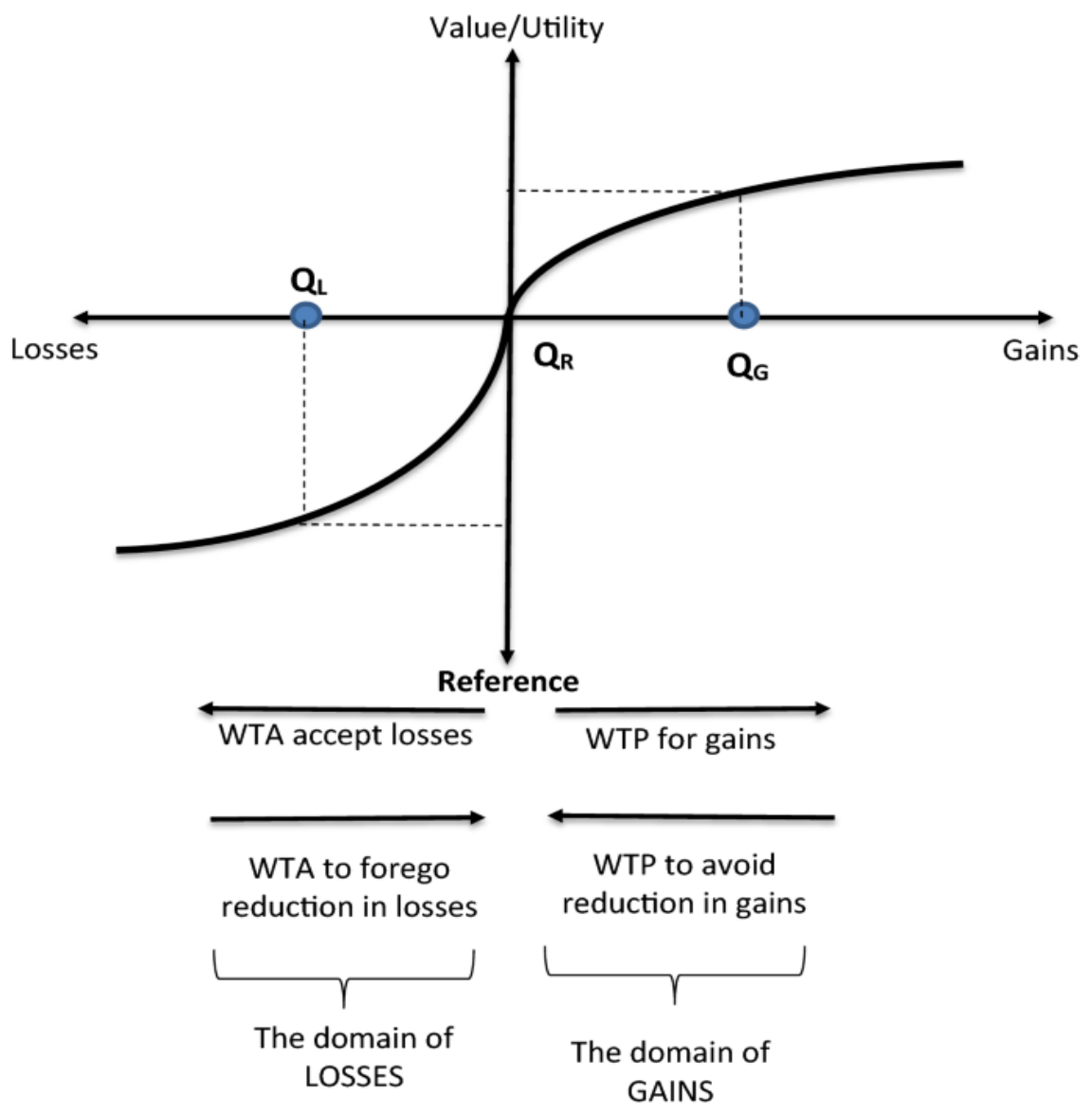

Fig. 1. Valuations of positive and negative changes relative to a reference state $(\mathbf{R})$

Source: Adapted from Nguyen et al. (2021)

The CVM method is based on the utility theory of Luce (1959) and McFadden (1973). Accordingly, the indirect utility function of households from implementing MSW classification to contribute to improving MSW management service has the following form:

$$
V(\boldsymbol{P}, q, M, \varepsilon)
$$

Where: $\mathbf{P}$ is the price vector, $q$ is the value of the quantity of the public good, $\mathrm{M}$ is income and $\varepsilon$ is the random error. For simplicity, we can remove the price vector from the indirect utility function and assume that the change in environmental goods is at the expense of households to perform MSW classification. Accordingly, when classifying MSW at source, the utility of a household has:

$\mathrm{V}\left(\mathrm{q}, \mathrm{M}+\mathrm{t}_{\mathrm{k}}, \varepsilon\right) \geq \mathrm{V}(\mathrm{q}, \mathrm{M}, \varepsilon)(2)$

In the $\mathrm{CV}$ scenario, the bid or cost of the program is suggested as $t_{k}$. The probability that the household chooses to answer "Yes" with the bid $t_{o}$ is:

$$
\operatorname{Pr}[Y e s]=\operatorname{Pr}\left[V\left(q, M+t_{k}, \varepsilon_{1}\right) \geq V\left(q, M, \varepsilon_{0}\right)\right]
$$

Assume that the utility function is linear and separability:

$$
v\left(q_{i}, M\right)+\varepsilon_{\mathrm{i}}
$$

Then, it is possible to write the probability formula (3) for the option "Yes" as:

$\operatorname{Pr}[$ Yes $]=\operatorname{Pr}\left[v\left(q_{1}, M+t_{k},\right)-v\left(q_{0}, M\right)+\varepsilon_{1}-\varepsilon_{0} \geq 0\right]$ (5)

The household will select "Yes" when the total utility changes, $\Delta U=v\left(q_{0}, M+t_{k},\right)-v\left(q_{i}, M\right)$, plus the difference in error, $\eta=\varepsilon_{1}-\varepsilon_{0}$, is greater than 0 . The probability is:

$$
\operatorname{Pr}[Y e s]=\operatorname{Pr}[\eta \geq-\Delta U]
$$

Based on the theory of probability, we have:

$$
\operatorname{Pr}[\text { Yes }]=\operatorname{Pr}[\eta \geq-\Delta U]=1-F_{\eta}(-\Delta U)
$$


Where $F_{\eta}$ is the cumulative probability function (CDF) of $\eta$. If $f(x)$ has a symmetrical distribution, then $F(x)=1-F(-x)$

If we assume that $\eta$ has a symmetrical distribution, we can write:

$$
\operatorname{Pr}[\text { Yes }]=F_{\eta}(\Delta U
$$

The cumulative probability function (CDF) describes the probability that a random variable $\mathrm{X}$ with a given probability distribution will be found at a value less than or equal to $X$. The probability density function (PDF) indicates the probability of the observation of a particular value of $\Delta \mathrm{U}$. The relationship between these two functions is given by $F_{\eta}(\Delta U)=\int_{-\infty}^{\Delta U} f(x) d x$, where $\mathrm{f}(\mathrm{x})$ is the $\mathrm{PDF}$. Thus the probability of an eigenvalue of $\Delta \mathrm{U}$ is also the area under the PDF curve.

The model is estimated by maximum likelihood. If $I_{k}$ represents the answer of the second observation $k$, with $I_{k}=1$ :

$$
\operatorname{Pr}[\operatorname{Yes}]=\operatorname{Pr}\left[I_{k}=1\right]=\operatorname{Pr}\left[\eta_{k} \leq \Delta U_{k}\right]=F_{\eta}\left(\Delta U_{k}\right)(9)
$$
with $I_{k}=0$ :

$$
\begin{aligned}
\operatorname{Pr}[N o] & =\operatorname{Pr}\left[I_{k}=0\right]=1-\operatorname{Pr}\left[\eta_{k} \leq \Delta U_{k}\right] \\
& =1-F_{\eta}\left(\Delta U_{k}\right)
\end{aligned}
$$

Then for each observation: $P_{r}\left(I_{k}\right)=$ $F\left(\Delta U_{k}\right)^{I_{k}}\left(1-F\left(\Delta U_{k}\right)^{1-I_{k}}\right.$

The likelihood function is written as:

$L=\prod_{k=1}^{N} \operatorname{Pr}\left[I_{k}=1\right] \operatorname{Pr}\left[I_{k}=0\right]=$

$\left.\prod_{k=1}^{N}\left[F_{\eta}\left(\Delta U_{k}\right)\right]^{I_{k}}\left[1-F_{\eta} \Delta U_{k}\right)\right]^{1-I_{k}}$

Where $\mathrm{N}$ is the number of observations. If we take the log function logically, we get the log-likelihood function as:

$$
\begin{aligned}
& \log L=\sum_{k=1}^{N}\left[I_{k} \ln F_{\eta}\left(\Delta U_{k}\right)+\left(1-I_{k}\right) \ln (1-\right. \\
& \left.\left.F_{\eta}\left(\Delta U_{k}\right)\right)\right]
\end{aligned}
$$

\subsection{Methodology}

\subsubsection{Data collection method}

Data for this research were collected from a survey of 578 respondents in four provinces in the Mekong Delta, including Can Tho City, Long Xuyen City (An Giang Province), Vi Thanh City (Hau Giang Province), and Vinh Long City (Vinh Long Province). According to a report by the Ministry of Natural Resources and Environment (2017), the rate of urbanization is one of the factors causing a sharp increase in MSW. Therefore, this research used the urban-type as a criterion for stratification. Can Tho city is urban-type 1 city, Long Xuyen city is an urban-type 2 city and Vi Thanh city and Vinh Long city are urban-type 3 cities (as classified at survey time in 2019). Then, the result of this study can be representative of the population in the MD.

The questionnaire included (1) Demographic information of respondents, (2) Situation of local solid waste management, amount of solid waste emissions and household scrap sorting and sale, and (3) the scenario describing the MSW management service reduction program and the question related to willingness to accept in the form of singlebounded questions.

Based on the information estimated by Can Tho Urban Public Works company (CUPW), the cost of all stages from MSW collection to treatment is 150,000 VND (upper bound). While the current average sanitation fee in MD is varied from 18,000 to 20,000 VND (lower bound). This fee is much lower than the actual fee that households have to pay because the Government is implementing a policy to compensate (or subsidy) currently. If the Government abolishes this policy, each household must pay a fee for domestic solid waste management service of $150,000 \mathrm{VND} /$ month. Then, we based on these upper and lower bounds, and divide them into 5 levels accordingly. Moreover, this is a hypothetical situation and to avoid being overestimated by the respondents in the WTA scenario, after subtracting 20,000 VND as the current amount that households must pay for current service. Therefore, five different bid values were chosen for the payment including 130,000 VND; 100,000 VND; 70,000 VND; 40,000VND; and 20,000 VND.

For example, in the WTA scenario for the bid level of 130,000 VND, respondents were asked:

"Assuming that to improve the efficiency of MSW management (in order to reduce the amount of MSW discharged into the environment), the Government implements a program to separate MSW at the source. This activity results in economic, environmental benefits and public awareness. Therefore, if a household segregates MSW at source, the fee to pay for SWM management service is less than 150,000 $\mathrm{VND} /$ month. Thus, if the fee for MSW management service is $150,000 \mathrm{VND} /$ month/household, and the household is required to classify at source to reduce the fee. 
Are you willing to classify so that the fee for MSW management service can be reduced from 150,000 $\mathrm{VND} /$ month to $20,000 \mathrm{VND} /$ month?

\subsubsection{Methods of data analysis}

The contingent valuation method estimates the mean and median of the willingness to accept based on the intercept of the regression model and the coefficient of the variable Bid, together with the coefficients of the variables of attitudes and other socio-economic characteristics. The Probit and Logit models are two commonly used models to analyze the factors affecting willingness to accept in the CVM. Based on the theory of a discrete CV data statistical model, this study applies the Logit model to estimate the probability that a household will accept an available bid (Hanemann \& Kanninen, 1984; Hanemann, 1999). The Logit model is presented as follows:

$$
P_{i}=P(Y=1)=F\left(x_{i}^{\prime} \beta\right)=\frac{e^{x_{i}^{\prime} \beta}}{1+e^{x_{i}^{\prime} \beta}}
$$

Where the dependent variable ( $\mathrm{Y}$ ) is a binary variable representing whether the respondent is willing to accept the MSW classification that contributes to the improvement of MSW management services. This variable takes two values, $\mathrm{Y}=1$, if the respondent agrees and $\mathrm{Y}=0$, if the respondent disagrees.

$$
\begin{gathered}
x_{i}^{\prime} \beta=\beta_{0}+\beta_{1} \text { Bid }+\beta_{2} \text { Age }+\beta_{3} \text { Gender }+ \\
\beta_{4} \text { Tdhvcap } 1+\beta_{5} \text { Tdhvcap } 2+\beta_{6} \text { Tdhvcap } 3+ \\
\beta_{7} \text { Tdhvtrencap } 3+\beta_{8} \text { Tnhap }+\beta_{9} \text { Dothiloai } 1+ \\
\beta_{10} \text { Dothiloai } 2+\beta_{11} \text { Taiche }(14)
\end{gathered}
$$

The independent variables include the variable Bid, which is the amount of money the respondent is willing to accept if they classify MSW at the source.

The variable Age is the age of the respondent (year). The variable Gender is a dummy variable that takes two values, Gender = 1 if respondent is male, and Gender $=0$, if respondent is female. The education level of respondents is included in the model by the variables Edu1, Edu2, Edu3, and Eduhigher3. The variable Edu1 is a dummy variable that takes two values, Edu $1=1$ if the respondent has a primary education, and otherwise. The variable Edu2 is a dummy variable that takes two values, Edu $2=1$ if the respondent belongs to the group with lower secondary education, otherwise Edu $2=0$. The variable Edu3 is a dummy variable that holds two values, while Edu $3=1$ if the respondent belongs to the group with an education in the upper secondary level, Edu3 = 0 when the respondent does not belong to the upper secondary education level. high school. The variable Eduhigher 3 is a dummy variable that takes two values, Eduhigher $3=1$ if the respondent is in the upper-secondary education group, and Eduhigher3 $=0$, if the respondent is not in the group with educational attainment above the high school. The coefficients of these variables are judged based on the comparison with the baseline group including respondents who did not attend school. The expected sign of these variables is positive because respondents with higher education levels will better understand the benefits of MSW classification at the source. The variable Income is the monthly income of the respondents (VND/month). The variable Recycle is a dummy variable that takes two values, Recycle $=1$ if the household did its MSW classification before it was collected by the urban sanitation worker, otherwise, Recycle $=0$.

The average willingness to accept compensation is calculated by the formula:

$$
E[W T A]=-\frac{\beta_{0}+\sum_{j=2}^{12} \overline{x_{J}} \beta_{j}}{\beta_{1}}
$$

\section{RESULTS AND DISCUSSIONS}

\subsection{Characteristics of the research respondents}

The majority of respondents $(66.26 \%)$ are women. Even in cases where there are many members at home, women often are respondents as they are considered the person involved in waste disposal. The average age of the respondents is 50.4 years and the average household size is 4.12 people. Only $11.59 \%$ of the respondents are single. The average number of years attending school is 8.37 years, with $71.78 \%$ of respondents having level 2 or above. The average monthly income of each household is 15.4 million VND/month, of which respondents contribute about $48.8 \%$ of the total income of the household. The average amount of MSW of households is about $1.8 \mathrm{~kg} /$ day (about $70 \%$ are organic ingredients). This amount of WSW is mostly collected by MSW management services. Since the study was conducted in urban areas, the majority of households (97.05\%) were provided with this service. There are $76.26 \%$ of households self-categorize recyclable materials to sell for scrap. In addition, households often sell scrap every month (the scrap sale period is every 28 days).

The first question in the WTP section is considered the basic question, which is related to the households' willingness to classify MSW. Result reveals that $65 \%$ of respondents self-classify MSW 
before it is collected by sanitation companies. In contrast, $35 \%$ of households do not self-classify MSW at the source. Interestingly, even though households have not done the classification themselves, but when they have introduced the
MSW management program, households still support the program with a high proportion of $85 \%$. Among the self-employed households, $10 \%$ of households still do not support the program. This result is summarized in Fig 2.

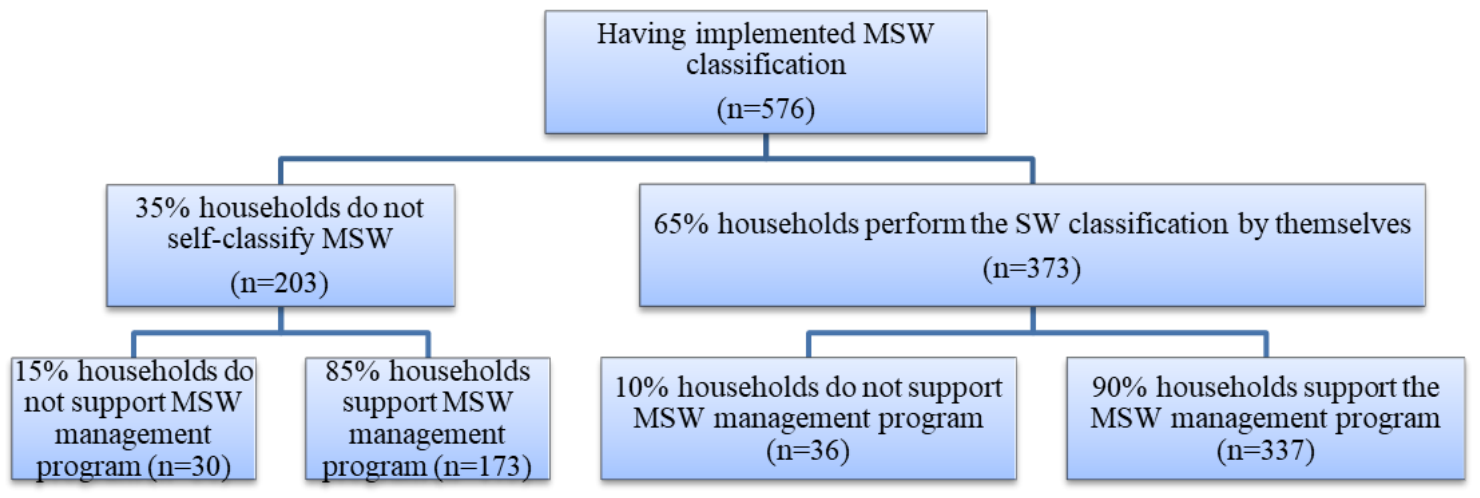

Fig. 2. Results of household responses for MSW management program

\subsection{The determinants of willingness to accept the waste reduction program}

The data shows that a total of $71.97 \%$ of the respondents agree to participate in the improved MSW management program and that $28.03 \%$ of the respondents do not agree to participate. The acceptance rate at each bid level is relatively high. Specifically, at the level of willingness to accept compensation of $130,000 \mathrm{VND} /$ month, $93.96 \%$ of the respondents agree, only $6.04 \%$ of the respondents disagree. When the bid decreased to $100,000 \mathrm{VND} / \mathrm{month}, 86.18 \%$ agreed. The number of people who agreed was reduced to $75.21 \%$ at the level of willingness to accept 70,000 VND/month. This rate of agreement continued to decrease to $59.13 \%$ when the willingness to accept decreased to $40,000 \mathrm{VND} / \mathrm{month}$. At the lowest willingness to accept compensation of $20,000 \mathrm{VND} /$ month, only $42.06 \%$ of the respondents agreed. Thus, the number of respondents who agreed to accept decreased gradually when the willingness to accept compensation for the behavior of classifying MSW at source decreased. This result is completely consistent with the economic theory of the supply curve.

Table 1. The proportion of respondents agreeing with the MSW classification at source

\begin{tabular}{lrrrrr}
\hline $\begin{array}{l}\text { Willingness-to- } \\
\text { accept } \\
\text { compensation } \\
\text { (VND/month) }\end{array}$ & $\begin{array}{r}\text { No. of } \\
\text { Observation }\end{array}$ & $\begin{array}{r}\text { Wumber of } \\
\text { respondents }\end{array}$ & $\begin{array}{rrrr}\text { Proportion } \\
(\%)\end{array}$ & $\begin{array}{r}\text { Number of } \\
\text { respondents }\end{array}$ & Proportion (\%) \\
\hline 130,000 & 116 & 109 & 93.96 & 7 & 6.04 \\
100,000 & 123 & 106 & 86.18 & 17 & 13.82 \\
70,000 & 117 & 88 & 75.21 & 29 & 24.79 \\
40,000 & 115 & 68 & 59.13 & 47 & 40.87 \\
20,000 & 107 & 45 & 42.06 & 62 & 57.94 \\
\hline Total & 578 & 416 & 71.97 & 162 & 28.03 \\
\hline
\end{tabular}

Source: Survey data, 2020

\subsection{Estimation of the willingness-to-accept (WTA)}

In order to test the robustness of influencing factors on the willingness to accept, table 2 presents the estimation results of the Logit model for 2 models.
Model 1 describes the effect of the independent variable Bid on households' willingness to accept compensation, and model 2 describes the Bid and household characteristics on the willingness to accept compensation. The estimation results show 
that the correct prediction percentage of model 1 is $74.91 \%$ and model 2 is $77.94 \%$, so it can be assessed that the correct prediction ability of both is acceptable. In other words, the willingness to accept compensation is affected by the independent variable Bid and other independent variables which are the socio-economic characteristics of the respondents.

Table 2. Logit regression results of factors affecting the households' willingness to accept

\begin{tabular}{|c|c|c|}
\hline \multirow{2}{*}{ Variables } & \multicolumn{2}{|c|}{ Coefficient } \\
\hline & Model 1 & Model 2 \\
\hline Constant & $-0.7921383^{\text {**** }}$ & $-3.4612^{* * * *}$ \\
\hline Bid & $0.0269696^{* * *}$ & $0.0306^{* * *}$ \\
\hline Age & & 0.0051 \\
\hline Gender & & -0.0552 \\
\hline Edu1 & & 0.3448 \\
\hline Edu2 & & $0.9931^{*}$ \\
\hline Edu3 & & $2.0387^{* * *}$ \\
\hline Eduhigher3 & & $1.2818^{* *}$ \\
\hline Income & & 0.0000153 \\
\hline Dothiloai1 & & $0.6855^{* *}$ \\
\hline Dothiloai2 & & $0.6466^{* *}$ \\
\hline Recycle & & $0.9849^{* * *}$ \\
\hline & Log likelihood $=-292.1601$ & Log likelihood $=-255.1107$ \\
\hline & $\operatorname{LR}_{\operatorname{chi}^{2}}(1)=101.44$ & $\operatorname{LR}_{\operatorname{chi}^{2}}(8)=157.46$ \\
\hline & Prob $>$ chi $^{2}=0.0000$ & Prob $>$ chi $^{2}=0.0000$ \\
\hline & Pseudo $\mathrm{R}^{2}=0.1479$ & Pseudo $\mathrm{R}^{2}=0.2358$ \\
\hline & Number of observations: 578 & Number of observations: 562 \\
\hline
\end{tabular}

Source: Survey data, 2020

Note: $*, * *, * * *$ are statistically significant at $10 \%, 5 \%$ and $1 \%$, respectively

In addition, the regression results also show that the estimated coefficient on the variable Bid is positive and statistically significant at $1 \%$ in both models, which means the higher bid for the classification of MSW at the source, the higher the probability the respondents agree. In addition, the results from model 2 also show that when respondents recycle MSW, the probability of acceptance is higher. Compared to the control group of respondents who did not attend school, respondents with education level 1, level 2, level 3, and above level 3 are more likely to accept the classifying MSW.

Groups of respondents in category 1 and 2 urbantype areas have a higher probability of accepting than those in category 3 urban-type areas do. This can be explained that in the category 1 and 2 urbantype areas, the MSW management system is relatively more complete than the category 3 urbantype, and people in the two areas have confidence in the improvement of the system with their contribution by the classification of MSW at the source. In addition, groups of households that selfclassify MSW to sell scrap have a higher probability of agreeing because they consider the MSW classification and scrap sale can contribute to environmental protection and achieve some extra money.

From the Logit model, the estimated results according to the parametric method reveal that the average WTA value of the people for MSW classification at source is about $30,000 \mathrm{VND} /$ month $(29,371.54 \mathrm{VND} / \mathrm{month} /$ household in model 1, and $29,986.49 \mathrm{VND} /$ month in model 2, respectively). In other words, if the assumption that the household's domestic MSW management fee subsidy policy is canceled and the household is facing a full fee for the MSW collection and treatment is 150,000 $\mathrm{VND} /$ month, the household is willing to perform the classification of MSW at source to receive a reduction of 30,000 VND. That means they accept a fee of about 120,000 VND/month.

Based on these findings, the research concludes that the implementation of the future policy may be appropriate in the current conditions in the MD by improving people's understanding of MSW, therefore, reducing pressure on the government budget by reducing the subsidy in the current policy. 
Table 3. The willingness to accept estimated by parametric approach

\begin{tabular}{rrrrrr}
\hline \multicolumn{2}{c}{ Items } & WTA & Lower bound & Upper bound & ASL \\
\hline \multirow{2}{*}{ Mean/median } & Model 1 & $29,371.54$ & $18,419.39$ & $37,650.72$ & 0.0000 \\
& Model 2 & $29,986.49$ & $19,273.13$ & $37,881.74$ & 0.0000 \\
\hline
\end{tabular}

Note: ASL is significance level for hypothesis testing: $H_{0}:$ WTA $<=0, H_{1}: W T A>0$

\section{CONCLUSION AND POLICY IMPLICATIONS}

In summary, the current situation of MSW management in the MD is similar to other regions in the country and other developing countries such as the limitation of collection and recycling activities. In addition, some stages of waste management activities such as collection, transportation, and treatment have not yet applied modern technology, but are mainly handled by manual labor. Therefore, the collection rate is only from $37 \%$ to $90 \%$. The remaining MSW that is not collected is disposed of improperly or dumped into rivers and canals. The final treatment of MSW includes landfilling, incineration, composting, and some application of modern technology. Therefore, with these limitations, the fact that more than $70 \%$ of respondents are willing to participate in the solid waste reduction program in this research is a very positive result, as can be considered as a basis for proposing a suitable recycling policy implementation.

\section{REFERENCES}

Arrow, K., Solow, R., Portney, P. R., Leamer, E. E., Radner, R., \& Schuman, H. (1993). Report of the NOAA panel on contingent valuation. Federal Register, 58(10), 4601-4614.

Carlsson, F., \& Martinsson, P. (2001). Do hypothetical and actual marginal willingness to pay differ in choice experiments?: Application to the valuation of the environment. Journal of Environmental Economics and Management, 41(2), 179-192. https://doi.org/10.1006/jeem.2000.1138

Can Tho City Department of Construction. (2018). Report on the supervision of the City People's Council on the implementation and management of daily-life solid waste in Can Tho city (No. 1958/BCSXD dated 18 September 2018).

Chien, Y. L., Huang, C. J., \& Shaw, D. (2005). A general model of starting point bias in doublebonded dichotomous contingent valuation surveys. Journal of Environmental Economics and Management, 50(2), 362-377. https://doi.org/10.1016/j.jeem.2005.01.002

Cooper, J. C., Hanemann, M., \& Signorello, G. (2002). One-and-one-half-bound dichotomous choice
Respondents in this survey are willing to accept the classification of MSW at the source of about 30,000 VND (equivalent to the fee of 120,000 $\mathrm{VND} /$ month). In the situation of MSW management fees will be canceled and the household faces a full fee for the MSW process (150,000 VND/month), they are willing to classify MSW at source to get a reduction of $30,000 \mathrm{VND}$. In other words, they accept a fee of about 120,000 VND/month. In addition, in the future, when implementing the official policy, policymakers need to pay attention to people experienced in MSW classification to motivate other people. In addition, people at a higher education level should also be prioritized to take part in the program at the initial stage.

\section{ACKNOWLEDGMENT}

This study is funded in part by the Can Tho University Improvement Project VN14-P6, supported by a Japanese ODA loan. We thank the two anonymous reviewers whose suggestions helped improve and clarify the paper.

contingent valuation. Review of Economics and Statistics, 84(4), 742-750. https://doi.org/10.1162/003465302760556549

Cummings, R. G., Harrison, G. W., \& Rutström, E. E. (1995). Homegrown values and hypothetical surveys: is the dichotomous choice approach incentive-compatible?. The American Economic Review, 85(1), 260-266.

Czajkowski, M., Kądziela, T., \& Hanley, N. (2014). We want to sort! Assessing households' preferences for sorting waste. Resource and energy economics, 36(1), 290-306. https://doi.org/10.1016/j.reseneeco.2013.05.006

Del Saz-Salazar, S., Hernández-Sancho, F., \& SalaGarrido, R. (2009). The social benefits of restoring water quality in the context of the Water Framework Directive: A comparison of willingness to pay and willingness to accept. Science of the Total Environment, 407(16), 4574-4583. https://doi.org/10.1016/j.scitotenv.2009.05.010

Diamond, P. A., \& Hausman, J. A. (1994). Contingent valuation: is some number better than no number?. Journal of economic perspectives, 8(4), 4564. https://doi.org/10.1257/jep.8.4.45 
Dupraz, P., Vermersch, D., De Frahan, B. H., \& Delvaux, L. (2003). The environmental supply of farm households: a flexible willingness to accept the model. Environmental and resource economics, 25(2), 171-189. https://doi.org/10.1023/A:1023910720219

Haab, T. C., \& McConnell, K. E. (2002). Valuing environmental and natural resources: the econometrics of non-market valuation. Edward Elgar Publishing. https://doi.org/10.4337/9781843765431

Hanemann, W. M. (1984). Welfare evaluations in contingent valuation experiments with discrete responses. American Journal of Agricultural Economics, 66(3), 332-341. https://doi.org/10.2307/1240800

Hausman, J. (2012). Contingent valuation: from dubious to hopeless. Journal of economic perspectives, 26(4), 43-56. https://doi.org/10.1257/jep.26.4.43

Karousakis, K., \& Birol, E. (2008). Investigating household preferences for kerbside recycling services in London: A choice experiment approach. Journal of environmental management, 88(4), 1099-1108. https://doi.org/10.1016/j.jenvman.2007.05.015

Laurent, A., Bakas, I., Clavreul, J., Bernstad, A., Niero, M., Gentil, E., Hauschild, M.Z.; \& Christensen, T. H. (2014). Review of LCA studies of solid waste management systems-Part I: Lessons learned and perspectives. Waste Management, 34(3), 573-588. https://doi.org/10.1016/j.wasman.2013.10.045

Mitchell, R. C., \& Carson, R. T. (2013). Using surveys to value public goods: the contingent valuation method. Rff Press.

Ministry of Natural Resources and Environment. (2019). National environmental status report 2019. http://vea.gov.vn/detail?\$id=1026
Nguyen, K. T., Knetsch, J. L., \& Mahasuweerachai, P. (2021). WTP or WTA: A Means of Determining the Appropriate Welfare Measure of Positive and Negative Changes When Preferences are Reference Dependent. Environmental and Resource Economics, 78(4), 615-633. https://doi.org/10.1007/s10640-021-00546-0

Ojok, J., Koech, M. K., Tole, M., \& OkotOkumu, J. (2012). Households' Willingness to Pay for Improved Municipal Solid Waste Management Services in Kampala, Uganda. Science Journal of Environmental Engineering Research, 2013, 1-8.

Pearce, D. W., \& Moran, D. (2013). The economic value of biodiversity. Routledge.

Peterson, L. G. (2003). A primer on nonmarket valuation (Vol. 3). P. A. Champ, K. J. Boyle, \& T. C. Brown (Eds.). Dordrecht: Kluwer Academic Publishers.

Small, N., Munday, M., \& Durance, I. (2017). The challenge of valuing ecosystem services that have no material benefits. Global Environmental Change, 44, 57-67. https://doi.org/10.1016/j.gloenvcha.2017.03.005

Singhirunnusorn, W., Donlakorn, K., \& Kaewhanin, W. (2012). Contextual factors influencing household recycling behaviours: A case of waste bank project in Mahasarakham municipality. Procedia - Social and Behavioral Sciences, 36, 688-697. https://doi.org/10.1016/j.sbspro.2012.03.075

General Statistics Office of Viet Nam. (2020). Report of the population and housing census 2019. https://www.gso.gov.vn/su-kien/2019/12/thong-cao-baochi-ket-qua-tong-dieu-tra-dan-so-va-nha-o-nam-2019/

Yuan, Y., \& Yabe, M. (2014). Residents' willingness to pay for household kitchen waste separation services in Haidian and Dongcheng districts, Beijing city. Environments, 1(2), 190-207. https://doi.org/10.3390/environments 1020190 